Patient Educ Couns. 2010 April ; 79(1): 124-129. doi:10.1016/j.pec.2009.07.028.

\title{
Beliefs About Exercise and Physical Activity Among Pregnant Women
}

\author{
Kelly R. Evenson ${ }^{1}$ and Chyrise B. Bradley ${ }^{1,2}$ \\ ${ }^{1}$ Department of Epidemiology, Gillings School of Global Public Health, University of North Carolina, \\ Chapel Hill, NC, USA \\ ${ }^{2}$ Carolina Population Center, University of North Carolina, Chapel Hill, NC, USA
}

\section{Abstract}

Objective: The objective of this study was to document self-reported beliefs about physical activity and exercise among pregnant women.

Methods: The Pregnancy, Infection, and Nutrition (PIN3) Study asked 1306 pregnant women about beliefs regarding physical activity and exercise at 27-30 weeks' gestation.

Results: While $78 \%$ of women agreed that most women can continue their regular exercise during pregnancy, fewer (68\%) agreed that most women who never exercised could begin an exercise program during pregnancy. Most (89\%) agreed that regular exercise was better than irregular exercise during pregnancy. While almost all women agreed with the benefits of light activity (98\%), fewer agreed that there were benefits with moderate $(73 \%)$ or vigorous exercise $(13 \%)$. Differences in beliefs were most notable by educational level, race/ethnicity, and whether they participated in regular exercise during pregnancy.

Conclusion: Future studies can better elucidate the reasons behind the differences in beliefs, to explore whether cultural reasons are contributing to these differences and whether tailored messages would be more effective than general educational approaches.

Practice Implications: This study provides information to create more successful interventions to help women understand concepts regarding the safety and benefits of physical activity during pregnancy.

\section{Keywords}

pregnancy; exercise; recreational activity; beliefs; cohort; physical activity; recommendations

\section{Introduction}

The American College of Obstetrics and Gynecology (ACOG) last provided exercise recommendations for women in 2002 [1], updating the 1994 guidelines [2]. Despite their

(C) 2009 Elsevier Ireland Ltd. All rights reserved.

Corresponding author at: Kelly R. Evenson, Bank of America Center, 137 East Franklin Street, Suite 306, University of NC, Gillings School of Global Public Health, Department of Epidemiology, Chapel Hill, NC 27514, kelly_evenson@unc.edu, phone: 919-966-4187, fax: 919-966-9800..

Publisher's Disclaimer: This is a PDF file of an unedited manuscript that has been accepted for publication. As a service to our customers we are providing this early version of the manuscript. The manuscript will undergo copyediting, typesetting, and review of the resulting proof before it is published in its final citable form. Please note that during the production process errors may be discovered which could affect the content, and all legal disclaimers that apply to the journal pertain. 
recommendation of physical activity for women without contraindications and the health benefits women may receive from being active during pregnancy [3], many pregnant women are not meeting these recommendations [4,5]. Pregnant women report that even with the wide range of information sources, including health care providers, family, friends, print materials, the internet, and the media, exercise is a topic that can be confusing or lack specificity [6-9]. In some cases, the health care provider's advice about exercise may be conservative with regards to intensity and dose or lacking altogether [8,9]. These reports from women are supported by surveys of obstetricians and gynecologists, in which a significant proportion report not discussing exercise with their pregnant patients $[10,11]$.

With the possible confusion about exercise during pregnancy, it brings into question just what women know and how well women understand concepts from the most recent ACOG guideline [1]. The purpose of this study was to further our understanding about the beliefs on exercise and physical activity among pregnant women. Specifically, we inquired about attitudes towards exercise and perceived benefits, constructs which are common in several health behavior models (e.g., health belief model, theory of planned behavior) [12]. We explored differences in beliefs by several factors in order to inform more tailored interventions.

\section{Methods}

\subsection{Study}

The third phase of the Pregnancy, Infection, and Nutrition (PIN3) Study recruited pregnant women <20 weeks' gestation seeking prenatal care at the University of North Carolina (UNC) Hospitals in Chapel Hill, NC. Women were not enrolled if they were non-English speaking, $<16$ years, carrying multiple gestations, not planning to continue care or deliver at the study hospital, or did not have a telephone from which they could complete the phone interviews. Recruitment occurred between 2001 and 2005. During this time, 3203 women were eligible for the study, 2006 were successfully recruited and provided written informed consent, and 1868 delivered at the UNC Hospital. The study website (http://www.cpc.unc.edu/pin) provides greater detail on the protocols and measures collected. All data collection described herein was approved by the UNC Institutional Review Board.

\subsection{Measures and Statistical Analyses}

Among those enrolled participants $(n=2006)$, we excluded those who had a second or third pregnancy during the study period $(n=131)$, such that participants were only included once. After further excluding those who did not complete the take-home questionnaire which included questions on beliefs about exercise $(n=569), 1306$ women remained for analysis. A description of the variables and covariates of interest can be found in Table 1. Beliefs were reported overall and explored for differences by covariates using a chi-square test statistic or Fisher's exact when sample strata were small (most data not shown). We used unconditional logistic regression to explore predictors of whether or not a woman agreed with each of the belief statements. All categorical variables were coded as indicator variables and Spearman correlations between variables were checked. All statistical analyses were conducted using SAS version 9.1.3 (Cary, NC).

\section{Results}

Women in the sample had a median age of 30 years, with other characteristics presented in Table 2 . The 15 belief questions are listed in Table 3 verbatim, along with the percent who agreed with each statement. While $78 \%$ agreed that most women can continue exercise during pregnancy, fewer $(68 \%)$ agreed that most women who never exercised could begin exercise during pregnancy. Less than $8 \%$ agreed that pregnant women could continue to exercise even 
if becoming tired or exhausted. Most (89\%) agreed that regular exercise was better than irregular exercise during pregnancy. Few (17\%) agreed that pregnant women should not exercise on their backs in the first trimester, but more agreed for second (64\%) and third trimester $(81 \%)$. Most agreed that standing without moving should be avoided $(93 \%)$. While almost all women agreed with the benefits of light exercise (98\%), fewer agreed that there were benefits with moderate (73\%) or vigorous exercise (13\%). Most also agreed that there were many benefits of physical activity during pregnancy: $94 \%$ agreed that exercise could increase energy, 94\% agreed that exercise could improve labor and delivery, and $75 \%$ agreed that exercise could improve the baby's health.

Many beliefs differed by whether or not the woman exercised 3 months before pregnancy or in the first or second trimester (Table 3). The most consistent difference across groups were among participants exercising in second trimester; these participants were much more likely to report that women can exercise during pregnancy and to report the positive benefits of exercise, compared to women not reporting exercise in the second trimester.

Next we conducted logistic regression predicting whether or not a woman agreed with each statement, controlling for all covariates shown in Table 4. Because of the high prevalence of agreeing that there is benefit in mild exercise, this model lacked prevision and is not presented. Correlations between the covariates of interest were generally low, with the strongest correlations between exercise before pregnancy and exercise during pregnancy $(0.53,95 \%$ confidence interval $0.49,0.58)$ and between marital status and education $(-0.49,95 \%$ confidence interval $-0.54,-0.43$ ).

General findings for the covariate results for each belief question, with the direction and strength of each odds ratio, are indicated in Table 4. Differences in beliefs were found to be most common by race/ethnicity, education, and participating in exercise during pregnancy. No differences were observed for marital status, general health, and physical activity advice from a health professional.

\section{Discussion and conclusion}

\subsection{Exercise during pregnancy}

Women were asked about their beliefs of continuing exercise during pregnancy. In our study, $22 \%$ of pregnant women disagreed with the question that most women can continue regular exercise during pregnancy. This belief can be contrasted with the ACOG guideline [1] that states that women can continue exercising regularly in pregnancy. This guideline also emphasizes that regular exercise is better than irregular exercise during pregnancy. Almost $90 \%$ of our sample agreed with a similar question that asked about regular exercise.

ACOG encourages women to be evaluated before starting a new exercise program [1]. Approximately two-thirds of our sample agreed that most women who never exercised could begin an exercise program during pregnancy. Less than $8 \%$ of the women agreed that it was acceptable for a pregnant woman to exercise even if becoming tired or exhausted. In retrospect, this question had limitations, such that the concepts of "tired" and "exhausted" are not identical and yet was used interchangeably. While it may have been acceptable to exercise when tired, it may not have been acceptable to exercise to exhaustion.

ACOG recommends avoiding exercise lying on the back during second and third trimesters, but not in first trimester [1]. We asked about supine exercise because we expected confusion could arise as to the time periods to avoid. Few (17\%) women agreed with the question that pregnant women should not exercise while lying on their back in the first trimester, but more 
agreed for second trimester (64\%) and third trimester (81\%). Most women agreed that standing without moving should be avoided, which is in line with the ACOG recommendation [1].

\subsection{Perceived benefits}

In our study, while almost all women agreed with the benefits of light activity (98\%), fewer agreed that there were benefits with moderate $(73 \%)$ or vigorous exercise $(13 \%)$. The benefit of differing intensities of exercise is not clearly delineated in the literature and the most recent ACOG recommendation recommends moderate intensity activity [1].

The women in our study were asked about other benefits of exercise, including improving labor and delivery, improving the baby's health, and being more energetic, all of which have some support in the literature [13-19]. Remarkably similar results were found in a study of 211 pregnant women attending a clinic in Mississippi [8]. In both ours and their study, 94\% agreed that exercise could improve labor and delivery and approximately three-fourths of the women believed that exercise could improve their baby's health.

\subsection{Limitations}

This study provides insight into the beliefs regarding exercise and physical activity among a large, diverse group of pregnant women. Despite these strengths, generalizability of this study may be limited, as the women were volunteers from central NC. Confirmation of these findings in other populations is needed. The reliability and validity of the questions about beliefs is not known. There are also other important beliefs that we did not query, such as the role of resistance exercise and general lifting during pregnancy. Moreover, the belief questions were developed prior to the release of the 2002 ACOG guidelines for exercise among pregnant women [1], but address many points in the guidelines due to reliance on past ACOG guidelines [2].

\subsection{Practice Implications}

Our results highlight groups of pregnant women more likely to have misconceptions about exercise that differ from the ACOG guidelines [1]. Even among women with appropriate understanding about exercise during pregnancy (according to our questions), many are not engaging in recommended levels of physical activity [20], despite their belief in health benefits both for themselves and for their babies (Table 3). More work is needed to understand what advice is being given to pregnant women from their health care providers and how to enhance the uptake of that advice.

\subsection{Conclusions}

Responses to beliefs about physical activity and exercise during pregnancy were most often different by race/ethnicity, education, and whether they participated in regular exercise during pregnancy. Future studies can better elucidate the reasons behind the differences in beliefs, to explore whether cultural reasons are contributing to these differences and whether tailored messages would be more effective than general educational approaches.

\section{Acknowledgments}

Acknowledgment Funding for this study was provided by the National Institutes of Health (NIH) / National Cancer Institute (\#RO1CA109804). Data collection was supported by NIH / National Institute of Child Health and Human Development (\#HD37584) and NIH General Clinical Research Center (\#RR00046). The content is solely the responsibility of the authors and does not necessarily represent the official views of the NIH. The Pregnancy, Infection, and Nutrition Study is a joint effort of many investigators and staff members whose work is gratefully acknowledged. We thank Fang Wen for assisting with the statistical analyses, Ginny Lee for reviewing an earlier draft of the paper, and the anonymous reviewers. 


\section{References Cited}

1. ACOG. Exercise during pregnancy and the postpartum period. ACOG Committee Opinion No. 267. Obstet Gynecol 2002;99(1):171-173. [PubMed: 11777528]

2. ACOG. Exercise during pregnancy and the postpartum period. ACOG Technical Bulletin Number 189--February 1994. Intl J Gynaecol Obstet 1994;45(1):65-70.

3. Pivarnik JM, Chambliss H, Clapp J III, Dugan S, Hatch M, Lovelady C, Mottola MF, Williams M. Impact of physical activity during pregnancy and postpartum on chronic disease risk. Med Sci Sports Exerc 2006;38(5):989-1006. [PubMed: 16672855]

4. Evenson K, Savitz D, Huston S. Leisure-time physical activity among pregnant U.S. women. Paediatric Perinatal Epidemiol 2004;18:400-407.

5. Pereira M, Rifas-Shiman S, Kleinman K, Rich-Edwards J, Peterson K, Gillman M. Predictors of change in physical activity during and after pregnancy: Project Viva. Am J Prev Med 2007;32:312-319. [PubMed: 17383562]

6. Clarke P, Gross H. Women's behavior, beliefs, and information sources about physical exercise in pregnancy. Midwifery 2004;20:133-141. [PubMed: 15177856]

7. Lewallen L. Healthy behaviors and sources of health information among low-income pregnant women. Public Health Nurs 2004;21(3):200-206. [PubMed: 15144364]

8. Krans EE, Gearhart JG, Dubbert PM, Klar PM, Miller AL, Replogle WH. Pregnant women's beliefs and influences regarding exercise during pregnancy. J Mississippi State Medical Association 2005;46 (3):67-73.

9. Doran F, O'Brien AP. A brief report of attitudes towards physical activity during pregnancy. Health Promot J Austr 2007;18(2):155-158. [PubMed: 17663652]

10. Entin P, Munhall K. Recommendations regarding exercise during pregnancy made by private / small grup practice obstetricians in the USA. J Sport Sci Med 2006;5:449-458.

11. Stafford R, Blumenthal D. Specialty differences in cardiovascular disease prevention practices. J Am Coll Cardiol 1998;32:1238-1243. [PubMed: 9809931]

12. National Cancer Institute. National Institutes of Health. US Department of Health and Human Services. Theory at a Glance: A Guide for Health Promotion Practice. Second Edition. Bethesda, MD: 2005. p. 52downloaded March 23, 2007 at http://www.nci.nih.gov/cancer_information/cancer_literature/

13. Sternfeld B. Physical activity and pregnancy outcome: Review and recommendations. Sport Med 1997;23(1):33-47.

14. Clapp J III. Morphometric and neurodevelopmental outcome at age five years of the offspring of women who continued to exercise regularly throughout pregnancy. J Pediatr 1996;129:856-863. [PubMed: 8969727]

15. Hall D, Kaufmann D. Effects of aerobic and strength conditioning on pregnancy outcomes. Am J Obstet Gynecol 1987;157:1199-1203. [PubMed: 3688075]

16. Magann E, Evans S, Newnham J. Employment, exertion, and pregnancy outcome: Assessment by kilocalories expended each day. Am J Obstet Gynecol 1996;175:182-187. [PubMed: 8694049]

17. Rice P, Fort I. The relationship of maternal exercise on labour, delivery and health of the newborn. J Sports Med Phys Fitness 1991;31:95-99. [PubMed: 1861491]

18. Rose N, Haddow J, Palomaki G, Knight G. Self-rated physical activity level during the second trimester and pregnancy outcome. Obstet Gynecol 1991;78:1078-1080. [PubMed: 1945211]

19. Schramm W, Stockbauer J, Hoffman H. Exercise, employment, other daily activities, and adverse pregnancy outcomes. Am J Epidemiol 1996;143:211-218. [PubMed: 8561154]

20. Borodulin K, Evenson K, Wen F, Herring A, Benson A. Physical activity patterns during pregnancy. Med Sci Sports Exerc 2008;40(11):1901-1908. [PubMed: 18845974] 
Table 1

Description of measures used in this study

\begin{tabular}{|c|c|c|}
\hline Measure & $\begin{array}{l}\text { Collection Period in } \\
\text { Gestational Weeks }\end{array}$ & Description \\
\hline Maternal age in years & medical record & $\begin{array}{c}\text { Age at time of conception was categorized as less than } 30, \\
\qquad 30-34, \\
\text { or } 35 \text { or more years. }\end{array}$ \\
\hline Race/Ethnicity & $\begin{array}{l}\text { phone interview at } \\
17-22 \\
\text { weeks }\end{array}$ & $\begin{array}{c}\text { Self-reported race/ethnicity was categorized as non-Hispanic } \\
\text { White, } \\
\text { non-Hispanic Black, or other. }\end{array}$ \\
\hline Marital status & $\begin{array}{l}\text { phone interview at } \\
17-22 \\
\text { weeks }\end{array}$ & $\begin{array}{l}\text { Marital status was categorized as either married or single, } \\
\text { separated, divorced, or widowed. }\end{array}$ \\
\hline Education & $\begin{array}{l}\text { phone interview at } \\
17-22 \\
\text { weeks }\end{array}$ & $\begin{array}{l}\text { Education was categorized as less than } 13 \text { years, } 13-15 \text { years, } \\
\text { or } \\
16 \text { or more years. }\end{array}$ \\
\hline Work status & $\begin{array}{l}\text { phone interview at } \\
27-30 \\
\text { weeks }\end{array}$ & $\begin{array}{l}\text { Work status during the past week of the interview was } \\
\text { categorized } \\
\text { as either working at least part-time or not working. }\end{array}$ \\
\hline General health & $\begin{array}{l}\text { phone interview at } \\
17-22 \\
\text { weeks }\end{array}$ & $\begin{array}{c}\text { General health was asked as excellent, very good, good, fair, } \\
\text { or } \\
\text { poor. }\end{array}$ \\
\hline & & $\begin{array}{c}\text { Self-reported weight and measured height were used to } \\
\text { determine } \\
\text { pre-pregnancy BMI. Values were grouped using the Institute } \\
\text { of } \\
\text { Medicine recommendations for pregnant women in effect } \\
\text { during } \\
\text { that time period as low }\left(<19.8 \mathrm{~kg} / \mathrm{m}^{2}\right) \text { or normal weight }(19.8- \\
<26.0\end{array}$ \\
\hline $\begin{array}{l}\text { Pregravid body mass } \\
\text { index } \\
(\mathrm{BMI}) \text { : }\end{array}$ & medical record & $\begin{array}{c}\left.\mathrm{kg} / \mathrm{m}^{2}\right) \text {, overweight }\left(26.0-<30.0 \mathrm{~kg} / \mathrm{m}^{2}\right) \text {, or obese }(>=30.0 \mathrm{~kg} / \\
\left.\mathrm{m}^{2}\right) \\
\text { [Institute of Medicine, } 1990 \# 1282] .\end{array}$ \\
\hline Parity & $\begin{array}{l}\text { phone interview at } \\
17-22 \\
\text { weeks }\end{array}$ & Parity was categorized as 0,1 , or 2 or more. \\
\hline $\begin{array}{l}\text { Physical activity advice } \\
\text { from health professional }\end{array}$ & $\begin{array}{l}\text { phone interview at } \\
27-30 \\
\text { weeks }\end{array}$ & $\begin{array}{c}\text { The question asked, "At any time during this pregnancy has } \\
\text { a } \\
\text { doctor, nurse, or other health professional told you to change } \\
\text { your } \\
\text { physical activity rather than follow your regular activity } \\
\text { routine?" } \\
\text { Response options were yes or no. }\end{array}$ \\
\hline $\begin{array}{l}\text { Exercise before and } \\
\text { during } \\
\text { pregnancy }\end{array}$ & $\begin{array}{l}\text { self-administered } \\
\text { questionnaire at } 24-29 \\
\text { weeks' }\end{array}$ & $\begin{array}{c}\text { The question asked, "We want to know about several } \\
\text { activities you } \\
\text { may have done outside of work. Have there been times when } \\
\text { you } \\
\text { have done any regular exercise or strenuous activity like } \\
\text { aerobic } \\
\text { exercise or jogging at least twice a week during... (1) the } 3 \\
\text { months } \\
\text { before you got pregnant, (2) the first } 3 \text { months after you got } \\
\text { pregnant, and (3) the second } 3 \text { months after you got } \\
\text { pregnant." } \\
\text { Response options were either "yes" or "no" and these similar } \\
\text { questions were used in the earlier PIN studies [Evenson, } 2002 \\
\text { \#1342]. Responses were grouped as exercising in neither } \\
\text { trimester, first or second trimester, or first and second } \\
\text { trimester. }\end{array}$ \\
\hline Beliefs about exercise & $\begin{array}{l}\text { self-administered } \\
\text { questionnaire at } 24-29 \\
\text { weeks' }\end{array}$ & $\begin{array}{c}15 \text { questions about beliefs regarding exercise and physical } \\
\text { activity } \\
\text { during pregnancy. Response options were either "agree" or } \\
\text { "disagree". }\end{array}$ \\
\hline
\end{tabular}


Table 2

Description of participants $(n=1306)$

\begin{tabular}{|c|c|c|}
\hline & $\mathbf{n}$ & $\%$ \\
\hline \multicolumn{3}{|l|}{ Maternal age in years: } \\
\hline$<30$ & 638 & 48.9 \\
\hline $30-34$ & 458 & 35.1 \\
\hline$\geq 35$ & 210 & 16.1 \\
\hline \multicolumn{3}{|l|}{ Race/Ethnicity: } \\
\hline Nonhispanic White & 944 & 72.5 \\
\hline Nonhispanic Black & 216 & 16.6 \\
\hline Other & 143 & 11.0 \\
\hline \multicolumn{3}{|l|}{ Marital status: } \\
\hline Married & 1011 & 77.5 \\
\hline Single/Separated/divorced/widowed & 294 & 22.5 \\
\hline \multicolumn{3}{|l|}{ Education in years: } \\
\hline$<=12$ & 249 & 19.1 \\
\hline $13-15$ & 241 & 18.5 \\
\hline$>=16$ & 816 & 62.5 \\
\hline \multicolumn{3}{|l|}{ Work status } \\
\hline Working at least part time & 835 & 66.3 \\
\hline \multicolumn{3}{|l|}{ General health } \\
\hline Excellent & 429 & 32.9 \\
\hline Very Good & 561 & 43.0 \\
\hline Good & 250 & 19.2 \\
\hline Fair/Poor & 64 & 4.9 \\
\hline \multicolumn{3}{|l|}{ Pregravid BMI $\left(\mathrm{kg} / \mathrm{m}^{\wedge} 2\right)$ : } \\
\hline Low $(<19.8)$ & 177 & 13.7 \\
\hline Normal (19.8-26.0) & 676 & 52.4 \\
\hline Overweight $(26.0<-29.0)$ & 140 & 10.8 \\
\hline Obese (>29.0) & 298 & 23.1 \\
\hline \multicolumn{3}{|l|}{ Parity: } \\
\hline 0 & 674 & 51.6 \\
\hline 1 & 421 & 32.2 \\
\hline 2 & 211 & 16.2 \\
\hline \multicolumn{3}{|l|}{ Physical activity advice from health professional } \\
\hline Yes & 295 & 23.5 \\
\hline \multicolumn{3}{|l|}{ Exercise before pregnancy } \\
\hline Yes & 736 & 65.7 \\
\hline \multicolumn{3}{|l|}{ Exercise during pregnancy } \\
\hline First trimester only & 185 & 16.5 \\
\hline Second trimster only & 115 & 10.3 \\
\hline Both first and second trimester & 303 & 27.0 \\
\hline Neither trimester & 518 & 46.2 \\
\hline
\end{tabular}




\begin{tabular}{ccc}
\hline & $\mathbf{n}$ & $\%$ \\
\hline Year beliefs survey completed & & \\
2001 & 146 & 11.2 \\
2002 & 302 & 23.2 \\
2003 & 328 & 25.2 \\
2004 & 330 & 25.4 \\
2005 & 195 & 15.0 \\
\hline
\end{tabular}




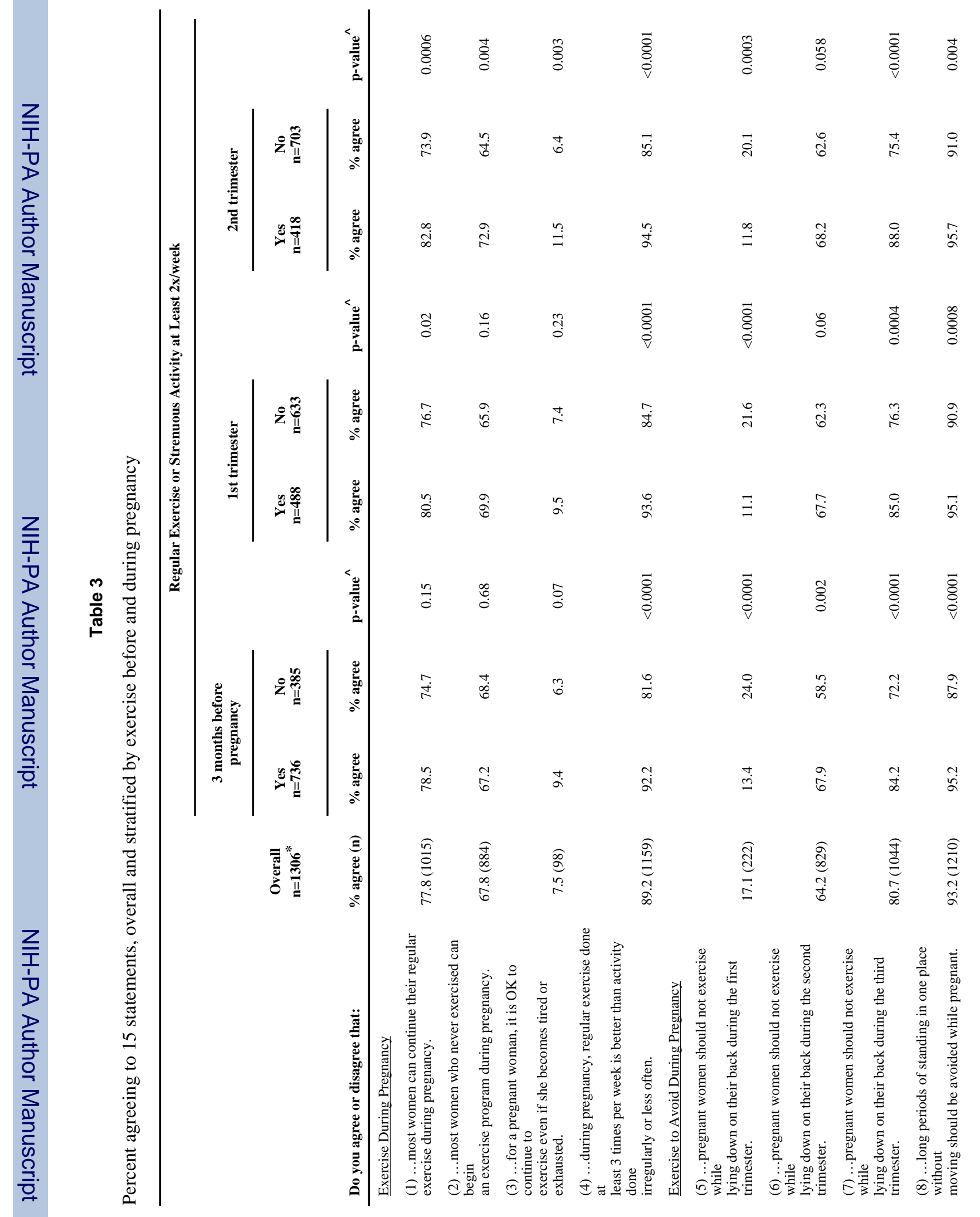

Patient Educ Couns. Author manuscript; available in PMC 2011 April 1. 


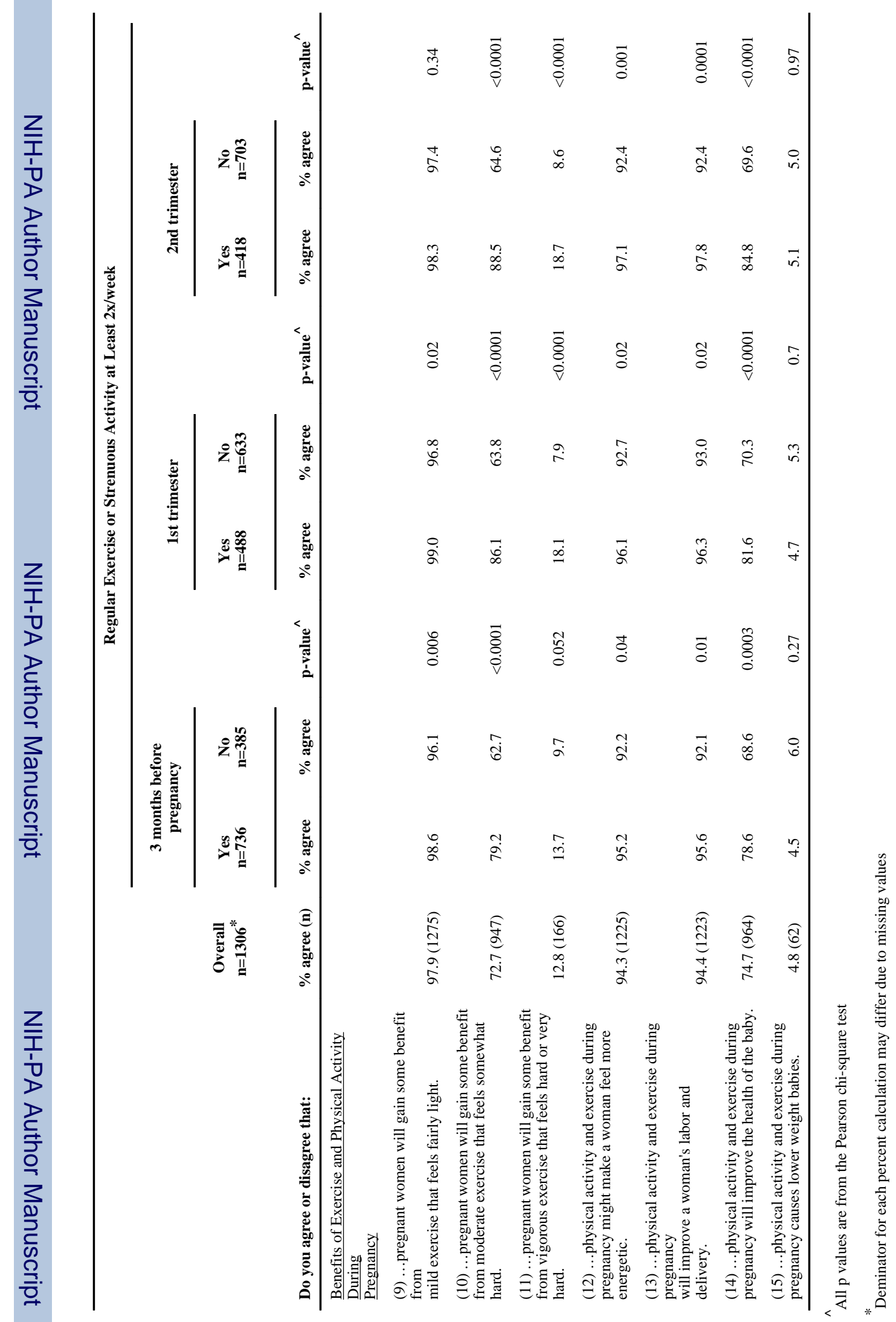

Patient Educ Couns. Author manuscript; available in PMC 2011 April 1. 


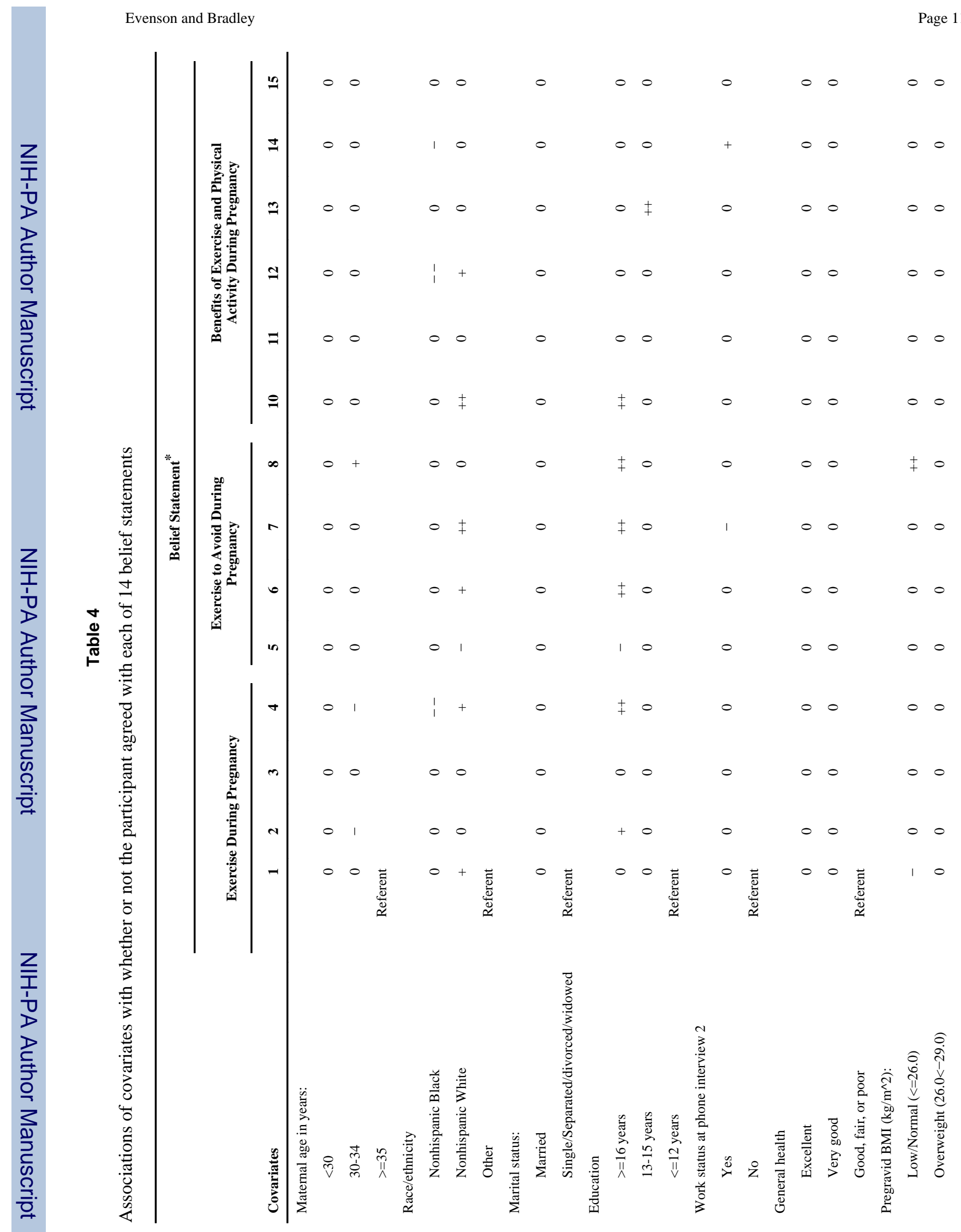

Patient Educ Couns. Author manuscript; available in PMC 2011 April 1. 


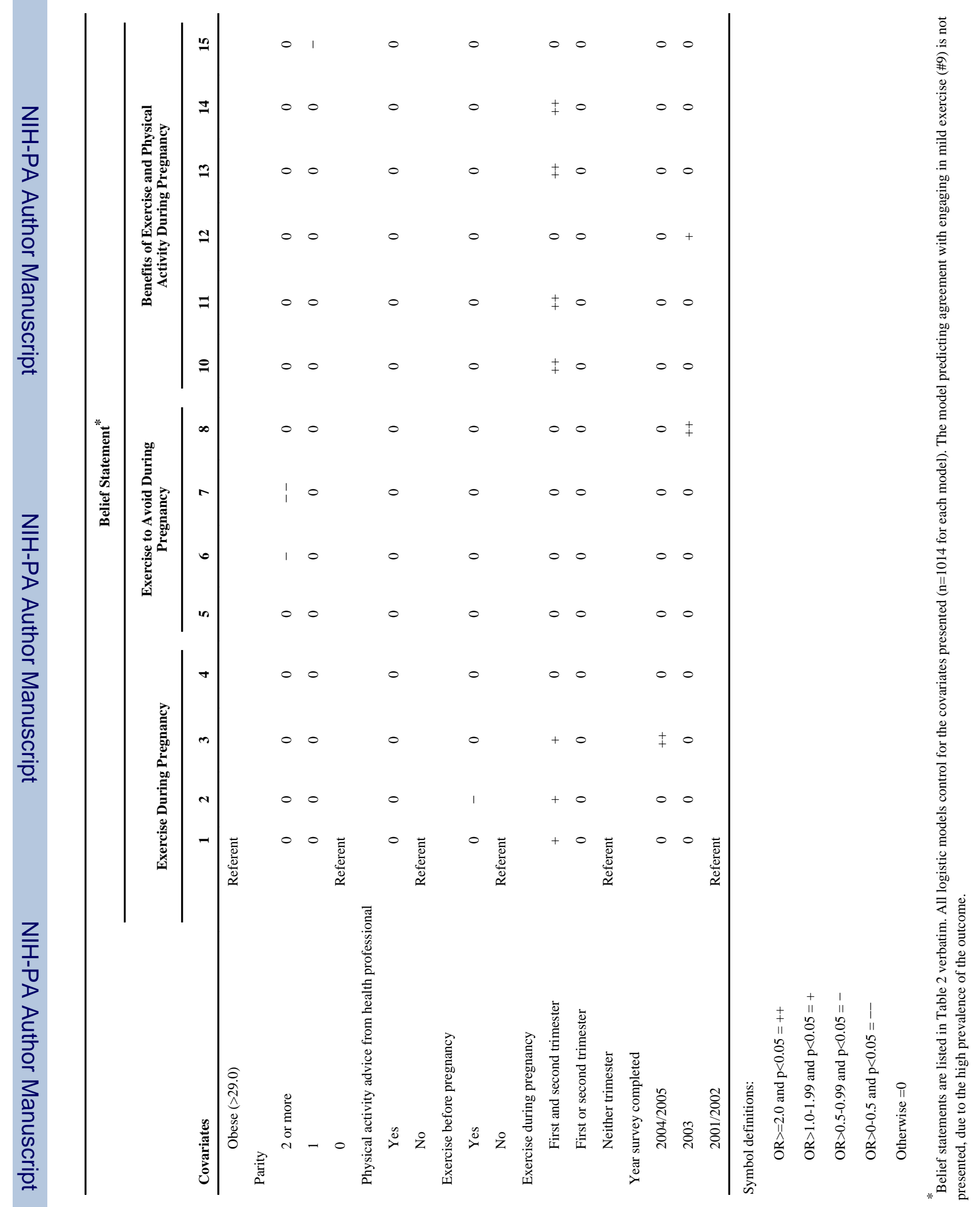

Patient Educ Couns. Author manuscript; available in PMC 2011 April 1. 